\title{
Estudo de poluição de recursos hídricos via equação diferencial ordinária
}

\author{
Gabriela C. Gonçalves \\ Saneamento Ambiental, FT, UNICAMP \\ 13484-332, Limeira, SP \\ E-mail: gabriela.cristinag@yahoo.com.br \\ Amanda de Cassia da Cunha \\ Mestrado em Tecnologia, FT, UNICAMP \\ 13484-332, Limeira, SP \\ E-mail: amanda_cunha1@yahoo.com.br
}

\section{Elaine Cristina Catapani Poletti}

Universidade Estadual de Campinas - Faculdade de Tecnologia

13484-332, Limeira, SP

E-mail: elainec@ft.unicamp.br

\section{RESUMO}

A água é um recurso natural de extrema importância à vida, aplicada ao consumo humano e animal, recreação, irrigação e proteção da vida aquática, sendo assim um recurso indispensável à vida [3], [2].

Atualmente, é crescente a preocupação da sociedade com a qualidade das águas dos corpos aquáticos, por estar apresentando altas quantidades de cargas poluidoras que foram geradas por meios antropológicos. As principais fontes de contaminações dos recursos hídricos são a poluição urbana, resíduos sólidos, os lançamentos de efluentes sem tratamento, de origem industrial e doméstica, além do uso excessivo de agrotóxico [1], [5]. Todos esses fenômenos seguem prejudicando os mananciais, deixando-os impróprios para os seres humanos e para a biota [4].

O objetivo da pesquisa é analisar o impacto ambiental, causados por poluentes em corpos aquáticos, através de uma equação diferencial ordinária via modelagem matemática.

Uma equação diferencial é uma equação com incógnitas de uma função que aparece na equação sob a forma das respectivas derivadas [6]. A ideia do estudo é avaliar o comportamento evolutivo de poluentes em função do tempo. A equação é utilizada por Alves [1] e consiste em uma equação diferencial ordinária de primeira ordem linear dada por:

$$
\frac{d c}{d t}+(f+d) c=q
$$


onde $c=c(t)$ indica a concentração de poluente na água; $f$ indica o fluxo do corpo hídrico; $d$ representa a degradação do poluente, e $q$ representa o ingresso de poluente.

O modelo, indica a taxa de variação da concentração de um dado poluente, num corpo aquático, em função do tempo, sendo assim de natureza contínua.

A equação (1), é denominada ordinária, pois depende de uma única variável independente: $t$. Além disso é caracterizada como de primeira ordem, pois escreve-se em termos da primeira derivada da função desconhecida $c(t)$, e é linear, pois seus coeficientes são termos lineares da função desconhecida $c=c(t)[6]$.

A resolução da equação (1) é realizada com base em [6] e a solução é dada por:

$$
c=c(t)=K e^{-(f+d)}+\frac{q}{(f+d)}
$$

O referido modelo possibilita a análise do comportamento evolutivo em função do tempo, da concentração de poluente em um copo aquático. A partir da solução da equação é possível, com parâmetros específicos de um dado corpo aquático, avaliar os cenários no tocante aos problemas de impacto ambiental e estudar estratégias tanto de preservação quando de recuperação que possam contribuir com o ecossistema.

Palavra-chave: Equações Diferenciais e Aplicações, Impacto Ambiental em Corpos Aquáticos, Modelagem Matemática.

\section{REFERÊNCIA BIBLIOGRÁFICA}

[1]- ALVES, L. F. B. Modelagens Matemáticas para Simulações Computacionais de Impacto Ambiental no rio Balsas. Dissertação de Mestrado Profissional em Matemática-Instituto de Matemática, Estatística e Computação Cientifica, Universidade Estadual de Campinas, São Paulo. 2009.

[2]- CONSELHO NACIONAL DO MEIO AMBIENTE-CONAMA. 1986. Resolução Conama $n^{\circ}$ 2. Disponível em: <http://www.mma.gov.br/port/conama/res/res86/res2086.html>. Acessado em 30 de novembro de 2013.

[3]- MELO, R.T. Modelos Matemáticos para Dispersão de Poluentes: Análise da dispersão de esgotos descartados em trechos urbanos do Rio Capibaribe. 2009. 106 f. Tese (Mestrado em Desenvolvimento de Processos Ambientais) -Universidade Católica de Pernambuco. Próreitoria Acadêmica. Coordenação Geral de Pós-graduação. Curso de Mestrado em Desenvolvimento de Processos Ambientais. 2009.

[4]-MINISTÉRIO DO MEIO AMBIENTE - MMA. Disponível em: <http://portal.mec.gov.br/dmdocuments/publicacao8.pdf >. Acessado em 29 de dezembro de 2013.

[5]- MONTOVANI, C.P. Presença de Fósforo e Modelagem de seu Comportamento Evolutivo no reservatório do Tatu. 2012. 106 f. Dissertação de Mestrado em Tecnologia - Faculdade de Tecnologia, Universidade Estadual de Campinas, São Paulo. 2012.

[6]- ZILL, D. G. Equações Diferenciais com Aplicações em Modelagem. São Paulo, SP: Pioneira Thomson Learning, 2003. 492 p. 